\title{
Cutaneous myiasis due to Tumbu fly
}

\author{
A. S. JAMES \& J. STEVENSON
}

Accident and Emergency Department, Victoria Infirmary, Glasgow

\section{SUMMARY}

A case of cutaneous myiasis due to larvae of the Tumbu fly Cordylobia anthropophaga is reported. The clinical presentation, treatment and prevention of this infestation is described.

\section{INTRODUCTION}

The current ease and speed of travel to exotic foreign locations has led to an increased likelihood of patients importing diseases rarely seen by practitionerso whose training has been confined to the United Kingdom.

A case of cutaneous myiasis due to Tumbu fly larvae presenting to an urban A\&E department is reported.

\section{CASE REPORT}

A 26-year-old professional golfer presented to the A\&E Department one day after returning from a 3-month golfing tour in Nairobi, Kenya.

He complained of pain and intolerable itching affecting the skin of his upper back for two days and had noticed a number of small 'boil like' blisters over the same area for 5 days. These had failed to respond to Amoxycillin/Clavulanic acid prescribed by his General Practitioner.

On examination there were 12 , raised, ovoid lesions in a line across the mid scapular region resembling furuncles. These ranged from $0.5 \mathrm{~cm}$ to $1.0 \mathrm{~cm}$ in diameter and each was surrounded by an area of induration and a ring of erythema. serous fluid and a total of 12 live maggots were expressed. (Fig. 1) These varied from $4-8 \mathrm{~mm}$ in length. The now collapsed lesions were covered with dry serous fluid and a total of 12 live maggots were expressed (Fig. 1). These varied

Correspondence: Mr J. Stevenson, FRCS, Senior Registrar in Accident and Energency Medicine, Sunderland District General Hospital, Kayll Road, Sunderland SR4 7TP. 


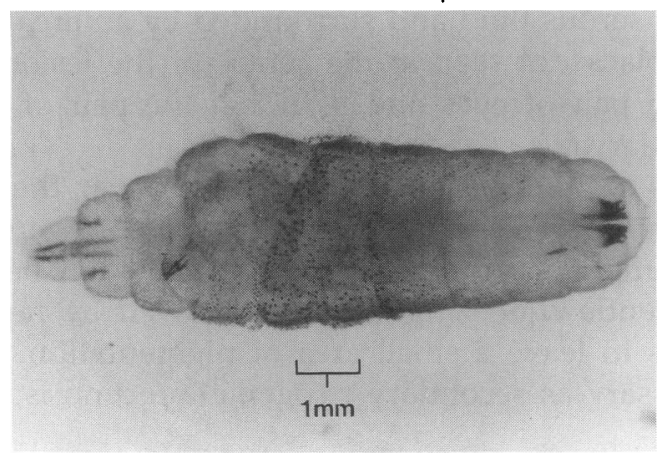

Fig. 1. Photomicrograph of third stage larva of the Tumbu fly Cordylobia Anthropophaga removed from.one of the lesions described. The dark tracheal tubes at the posterior end of the larva are clearly seen.

from 4-8 $\mathrm{mm}$ in length. The now collapsed lesions were covered with dry dressings. On review $48 \mathrm{~h}$ later all showed evidence of healing and the patient was asymptomatic. The maggots were later identified as larvae of the Tumbu fly (Cordylobia anthropophaga).

\section{DISCUSSION}

Myiasis (invasion of vertebrates by larval flies) is rare in the United Kingdom and only a handful of cases of cutaneous myiasis due to infestation by the larvae of the Tumbu fly have been reported. (Anonymous, 1972; Wildy \& Glover, 1982; Chopra et al., 1985).

'Furuncular' cutaneous myiasis due to Tumbu fly larvae occurs in previously healthy unbroken skin and must be differentiated from cutaneous 'wound' myiasis more commonly seen in this country following infestation of wounds or diseased tissue by the larvae of flies such as the bluebottle (Calliphora vomitora and vicina, Zumpt, 1965; Alexander, 1984).

The definitive study on the Tumbu fly (Cordylobia anthropophaga) was carried out in Sierra Leone in 1923 (Blacklock \& Thompson, 1923). The fly is prevalent in tropical and sub tropical Africa south of the Sahara. The principal hosts of the larvae are wild rodents but domestic animals, dogs and man may become infested.

The female lays approximately 300 eggs on clothing, particularly if sweat impregnated, bed linen, or on dry sand contaminated with urine or faeces, preferring shaded areas away from direct sunlight. The eggs hatch in 2-4 days and the larvae, on contacting skin, either via clothing or from the ground, painlessly burrow into the sub-dermal layer. Pain and itching occur with the development of the blister like lesions. If left untreated the larvae fall from the skin after 15 days and enter a 3 week pupatory phase ending in the emergence of the adult fly.

Normally only one or two larvae affect the human host usually over the arms, shoulders, axillae, legs or scrotum. The skin lesion is typically described as resem- 
bling a boil, exuding serous fluid and surrounded by an area of tender induration. (Fig. 2) The mobile black dot seen in the centre of the lesion if closely examined is said to resemble a pair of eyes and is in fact the pair of tracheal tubes at the posterior end of the larva.

Treatment consists of removal of any small scab over the lesion and applying a layer of liquid paraffin. This stimulates the larva to reverse out of the skin to bring the tracheal tubes in contact with air. It can then be painlessly removed using forceps and gentle squeezing. This is followed by rapid resolution of the furuncle which heals to leave a small area of pigmentation. (Figure 3) Antibiotic treatment is unnecessary as secondary pyogenic infection is unusual.

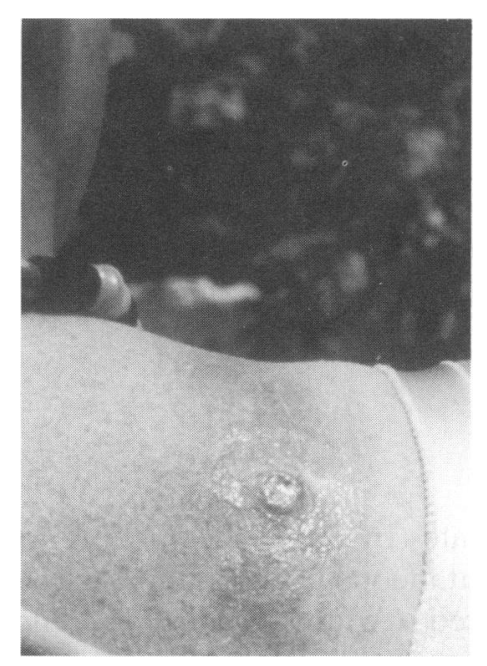

Fig. 2. Photograph of skin lesion caused by infestation with the larva of the Tumbu fly on the shoulder of a female patient.

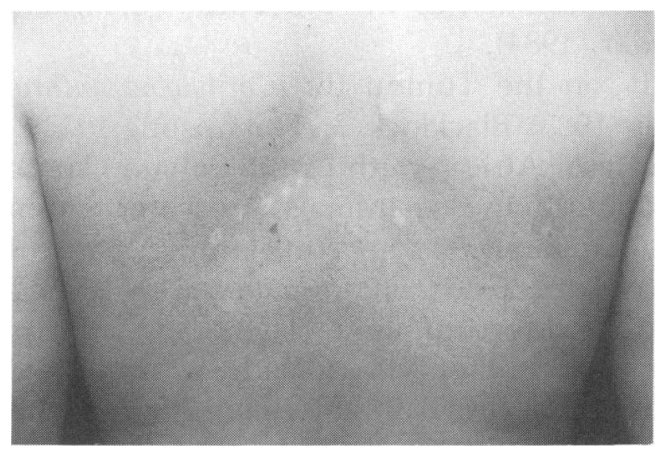

Fig. 3. Photograph of the healed lesions 3 weeks after initial presentation on the back of the patient described. A central area of pigmentation surrounded by an area of depigmentation is seen for each lesion. 
Prevention is suggested by leaving clothing and bed linen to air clear of the ground in bright sunlight. Careful ironing of clothing paying particular attention to the seams kills any eggs contained in the material.

Cutaneous myiasis often evokes revulsion both in the patient and the attending physician, partly due to the commonly held misconception that maggot infestation occurs only in dirty debilitated patients as a result of poor hygiene. Awareness of the condition and understanding of the disease process allows early diagnosis and treatment and facilitates informed reassurance of the patient.

\section{ACKNOWLEDGEMENTS}

We wish to thank Mr I. W. R. Anderson, Consultant, Accident and Emergency Department Victoria Infirmary Glasgow for permission to report on this patient and Dr M. J. Colloff, Department of Zoology, University of Glasgow for identifying the larvae and providing the photographs.

\section{REFERENCES}

Alexander J. O'D. (1984) Arthropods and the human skin, 87-113. Springer-Verlag, New York. Anonymous. (1972) Tumbu Fly. British Medical Journal 2, 58.

Blacklock B. \& Thompson M. G. (1923) A study of the Tumbu fly Cordylobia anthropophaga, Grünberg in Sierra Leone. Annals of Tropical Medicine and Parasitology 17, 443.

Chopra A., Probert A. J., Beer W. E. (1985) Myiasis due to Tumbu fly. (letter) Lancet 1, 1165. Wildy G. S., Glover S. C. (1982) Myiasis due to Tumbu fly larvae. (letter) Lancet 1, 1130.

Zumpt F. (1965) Myiasis in man and animals in the Old World, p. 70-4, Butterworths, London. 